\title{
Espacios de ocio en la territorialidad Guaraní Kaiowá de Dourados, Mato Grosso do Sul, Brasil
}

\author{
Marina VINHA \\ Universidade Federal da Grande Dourados (UFGD), Brasil. \\ marinavinha@ufgd.edu.br \\ Maria Beatriz ROCHA FERREIRA \\ Universidade Estadual de Campinas, Brasil \\ beatrizdevloo@aim.com \\ Adir CASARO NASCIMENTO \\ Universidade Católica Dom Bosco (UCDB), Brasil \\ adir@ucdb.br
}

Recibido: 10-09-2012

Aceptado: 19-12-2012

\begin{abstract}
Resumen
En Brasil la población indígena alcanza aproximadamente las 817 mil personas. En el Estado de Mato Grosso do Sul habita una gran parte de ellas: solamente el pueblo Guaraní y sus variedades suponen una población de 47 mil personas distribuidas en 26 aldeas extendidas a lo largo de 18 municipios. Las tierras indígenas forman parte legítima del Estado-nación y están judicialmente vinculadas a los municipios. Junto a este encuadramiento legal, dichas tierras exceden su propio límite espacial, constituyéndose como identidades para cada pueblo. Las tierras y los territorios se transforman en territorialidades, cuyos significados requieren estudios específicos sobre los elementos culturales de cada etnia. Esta investigación se ocupa exclusivamente del municipio de Dourados, en la Reserva Indígena Francisco Horta, y tiene como propósito comprender las figuraciones del ocio o del alevezar (aligerar) por medio de la reflexión sobre la cartografía de sus espacios lúdicos. El estudio aborda las resistencias y los cambios que temporalizan las formas lúdicas en el contexto del patrimonio cultural indígena. Sus objetivos son: (i) aprehender el significado de la territorialidad Guaraní; (ii) identificar los espacios de ocio registrados por los indígenas en los mapas de sus aldeas; (iii) interrelacionar territorialidades y espacios de ocio. La metodología abarca: (a) revisión bibliográfica de los textos eliasianos que abordan la cuestión del ocio; (b) reflexión y elaboración del sentido de ocio para los indígenas e identificación del mismo mediante el término alevezar; (c) selección de uno de los espacios representados en un mapa de alevezar realizado por los alumnos indígenas; (d) criterios para sistematizar ese espacio, asociándolo con las posibles actividades practicadas. Los resultados del estudio amplían la comprensión de los conceptos de ocio de este pueblo. El estudio de los espacios de ocio mostró un número superior de espacios para deportes y un número inferior de espacios dedicados al ocio tradicional. Estos hechos representan procesos de larga duración relativos a las relaciones del mundo tribal Guaraní con la sociedad en general; mundo tribal sometido a los procesos de coerción y autorregulación e inclusive a condiciones de violencia como las vividas a lo largo de los dos últimos siglos.
\end{abstract}

Palabras clave: ocio, lúdico, patrimonio cultural, pueblo Guaraní, indios de Brasil. 


\title{
Leisure spaces in dourados kaiowá/guarani territoriality, state of mato grosso do sul, brazil
}

\begin{abstract}
In Brazil, indigenous population is about 817 thousand people, and a great part of such people lives in the State of Mato Grosso do Sul, and only the Guarani people and their variation reach a population of 47 thousand, distributed in 26 villages spread throughout in 18 municipalities. Indigenous lands are legally owned by the Brazilian nation state, and judicially bonded with each municipality where they are located. Besides this legal context, they exceed their physical borders and assume identity meanings of each people. Lands and territories become territorialities whose meanings require the study of several elements of each ethnic group. This research, conducted in Francisco Horta Indigenous Land in Dourados municipality, aims to understand the figurations of leisure, or alevezar*, through the reflections that came with the mapping process of their ludic spaces. This study approaches the resistances and changes, which contemporize the ludic forms in the cultural heritage context. The objectives are: (i) to learn the meaning of guarani territoriality; (ii) to identify the leisure spaces registered by the indigenous people in their villages' maps; and (iii) to establish the relationship between territoriality and leisure spaces. The methodology comprises: (a) the bibliographical review of texts from the Nobert Elias theory related to the leisure matter; (b) the reflection and elaboration of the meaning of leisure to the indigenous group, including the option for the term alevezar; (c) the selection of maps of alevezar spaces done by indigenous university students enrolled on the intercultural indigenous undergraduate course at the Faculty of Education, Federal University of Grande Dourados; and (d) the establishment of criteria to organize such spaces, associating them to the practice of activities. The results have partially broadened our understanding about the changes occurring in those people's way of living. Such facts represent long-term processes that intervene in the guarani tribal world, and reflect the insertion of those people in the general society, most of the time under coercive processes of self-regulation, including the condition of violence to which they have been submitted along the last two centuries.
\end{abstract}

Key words: leisure, ludic, cultural heritage, guarani people, Brazilian indigenous

\section{Referencia normalizada}

Vinha, M., Rocha Ferreira, M., Casaro Nascimiento, A. (2013). "Espacios de ocio en la territorialidad guaraní kaiowá de dourados, mato grosso do sul, brasil”. Política y Sociedad, Vol.50 Núm 2: 453-482

Sumario: Introducción. 1.Tierra y Territorialidad. 2.Tiempo, Espacio y Ocio. 3.Interrelaciones: Territorialidad y Espacios de Ocio. 4.Consideraciones Finales. Bibliografía.

\section{Introducción}

Brasil tiene 190.755.799 habitantes. De este total y según el Instituto Brasileño de Geografía y Estadística (IBGS, 2010), 817.000 personas se declaran indígenas, lo que supone aproximadamente el $0,42 \%$ de la población del país. Este número, como apunta Agostinho (Ecoamazonia, 2011), representa un crecimiento del 11\% en relación al registrado en el Censo del año 2000, cuando 734.000 personas se declaraban como tales. La reciente conquista de la condición de ciudadanía 
conforme a la Constitución de 1988 fortaleció a 220 pueblos ${ }^{1}$ y sus correspondientes 180 lenguas, incluyendo a aquellos que sólo hablan portugués al haber incorporado la lengua del colonizador.

Las Tierras Indígenas (TIs) en Brasil pertenecen legalmente al Estado-nación y están vinculadas judicialmente a diferentes municipios. Más allá de este contexto legal, las mismas no se reducen a sus límites espaciales y se transforman en significados identitarios para cada grupo étnico. Tierras y territorios conforman territorialidades, cuyos significados requieren el estudio de los elementos constitutivos de cada pueblo a fin de ser comprendidos y respetados en sus diferencias. En común, las TIs poseen un vínculo con la cosmología de cada etnia, hecho que ha conducido a los indígenas brasileños a una larga, ardua y sangrienta lucha $^{2}$ contra el Estado-nación y los 'Estados-nacionales, ${ }^{3}$ con el propósito de materializar sus derechos. El Estado de Mato Grosso del Sur (MS) reúne a la segunda mayor población indígena ${ }^{4}$ del país tras la que se asienta en la Amazonia Legal.

El gran pueblo Guaraní está distribuido por diez estados brasileños. Conocido como el 'pueblo de la selva' - el propio nombre Kaiowá procede de esa denominación, aclara Colman (2007) - , los subgrupos 'Guaraní Mbyá', 'Guaraní Ñandeva’ y 'Guaraní Kaiowá’ son miembros del árbol ${ }^{5}$ lingüístico tupi-guaraní. En MS viven dos de esos subgrupos, los Guaraní Kaiowá y los Guaraní Ñandeva: juntos suponen un total de 47.000 ciudadanos distribuidos en 29 aldeas al sur del Estado ${ }^{6}$.

A lo largo del texto se adopta la denominación Kaiowá/Guaraní en detrimento de la denominación Guaraní Kaiowá, esta última procedente de estudios recientes que priorizan el mayor peso demográfico de los Kaiowá. Los Kaiowá/Guaraní disponen de una organización muy respetada tanto nacional como

\footnotetext{
${ }^{1}$ En el momento de la llegada de los colonizadores se estima que unos 2000 pueblos vivían en estas tierras.

${ }^{2}$ Para profundizar en las cuestiones de la tierra indígena en Brasil, se sugiere la lectura de artículos vinculados al Consejo Indigenista Misionero [Conselho Indigenista Missionário (CIMI) [www.cimi.org.br]; el Instituto Socioambiental (ISA) [www.socioambiental.org.br] y el Núcleo de Estudios e Investigaciones sobre Poblaciones Indígenas [Núcleo de Estudos e Pesquisas em Populações Indígenas (NEPPI) www.neppi.org.br]

${ }^{3}$ Actuales relaciones y políticas propiciadas por el MERCOSUR (Brand, Azevedo e Colman:2011).

${ }^{4}$ Las etnias que habitan MS son: Ofaié, Guató, Kadiweu, Kinikinau, Terena, Kaiowá, Guarani y Atikum.

${ }^{5}$ Clasificación de las etnias según la familia lingüística.

${ }^{6} \mathrm{El}$ total de 29 aldeas se refiere a las áreas indígenas, demarcadas o no, incluyendo las 8 reservas demarcadas a comienzos del siglo XX. El Estado está formado por 67 municipios.
} 
internacionalmente, la Aty Guassu ${ }^{7}$ (Gran Asamblea), un espacio político deliberativo en el que participan los líderes culturales y políticos para discutir los problemas existentes en las comunidades indígenas.

En este contexto, el presente artículo ${ }^{8}$ problematiza las figuraciones territoriales del ocio de los indígenas Kaiowá/Guaraní adscritos al municipio de Dourados ${ }^{9}$ en MS. Una parte de los mismos vive en la 'Tierra Indígena de Dourados' o 'Reserva Indígena Francisco Horta Barbosa'. Esta reserva se encuentra étnicamente compartida por dos aldeas - Bororó y Jaguapiru - que concentran, aproximadamente, unas 15.000 personas.

Al problematizar el ocio, concepto ampliamente utilizado en nuestro estudio, se abordan algunos de sus aspectos más relevantes. Uno de ellos, el de la esfera de la 'acción ${ }^{10}$ humana históricamente situada', versa sobre el derecho social conquistado en el proceso de construcción de la ciudadanía brasileña a partir de la Constitución de 1988, momento en el cual el ocio pasa a integrar la Carta Magna en las siguientes situaciones:

[...] Capítulo II, art. $6^{\circ}$ - De los Derechos Sociales, - [...] derechos sociales a la educación, a la salud, al trabajo, al ocio, a la seguridad, a la seguridad social, a la protección de la maternidad y la infancia, a la asistencia a los necesitados, en la forma de esta Constitución; Capítulo II, art. $7^{\circ}$, item IV, la Constitución reafirma que el ocio es un derecho de todo trabajador siendo el [...] salario mínimo, fijado por ley, nacionalmente unificado, capaz de atender a las necesidades vitales básicas e a las de su familia con vivienda, alimentación, educación, salud, ocio, vestido, higiene, transporte e protección social [...]. (Cursivas nuestras).

Los restantes aspectos en el tratamiento del ocio entre los Kaiowá/Guaraní requieren considerar su historia como grupo étnico en contacto regular con la sociedad no-indígena; grupo que vive en co-dependencia de relaciones externas con otros grupos étnicos y con la sociedad no-indígena regional (Junqueira, 2002). De entre la red de instituciones derivadas de esas interrelaciones externas destacan la escuela, la iglesia y los órganos gubernamentales específicamente destinados al indígena. Inicialmente, durante el proceso de contacto, las instituciones tenían por

${ }^{7}$ El movimiento político Guarani Kaiowá de Mato Grosso del Sur recibió el Premio de los Derechos Humanos 2010 concedido por la Secretaría de Derechos Humanos de la Presidencia de la República en la categoría "Garantía de los Derechos de los Pueblos Indígenas". La Aty Guasu lucha, desde los años 80, por la recuperación de las tierras Guarani Kaiowá. Los indígenas se mostraron satisfechos com este reconocimiento pero todavía aguardan a que las acciones de demarcación en MS avancen y que la violencia por parte de los hacendados y terratenientes termine (CIMI:2010).

${ }^{8}$ Investigación en curso parcialmente publicada en los Anais do XII Simpósio Internacional Processo Civilizador, cuya autoría corresponde a Vinha y Rossato (2009).

${ }^{9}$ Otros 17 municipios y sus correspondientes aldeas serán examinados a lo largo de 2012.

${ }^{10}$ Expresión adoptada por Marcellino (2000). 
objetivo 'civilizar' en el sentido de integrar, tal y como preconizaban las constituciones ${ }^{11}$ brasileñas anteriores a 1988. Por lo tanto, ser civilizado significaba sustituir el modo de ser indígena por un modelo occidentalizado de carácter genérico creando de esta forma una 'segunda naturaleza', que interviene en el patrón de comportamiento construyendo un habitus ${ }^{12}$ en lo que constituye una falta de respeto y un ocultamiento de la construcción cultural indígena. (Elias, 1980; Vinha y Nascimento, 2009). El habitus ${ }^{13}$, en sentido eliasiano, resulta consistente con la interrelación yo-nosotros [persona-grupo-sociedad] y tiene en el tiempo un elemento de influencia en la dinámica de esas relaciones. Para los indígenas, designa la condición de aceptación de la pérdida o delimitación de sus tierras en un proceso histórico que responde al modelo de 'competición primaria': la apropiación no es negociada y sí materializada a través de las relaciones de poder asimétricas establecidas por las élites económicas de la región en la que vivían y viven los indígenas (Elias, 1980).

En este sentido, el estudio que aquí se presenta tiene como objetivos (i) aprehender el significado de la territorialidad guaraní; (ii) identificar los espacios de ocio registrados por los indígenas en los mapas de sus aldeas; e (iii) interrelacionar territorialidades y espacios de ocio. El tema transversal a toda nuestra investigación es el ocio y sus manifestaciones en la jurisprudencia del derecho al ocio, en la concepción del tiempo de los indígenas Kaiowá/Guaraní y en el aprendizaje de ese ocio en el marco de sus aldeas. Todo ello, desde una óptica eliasiana, comprendido a la luz del prisma teórico de los procesos histórico-sociales de larga duración.

Esta investigación es de carácter descriptivo y se desarrolló de acuerdo con la siguiente metodología: (a) revisión de la bibliografía específica sobre los Kaiowá/Guaraní y la teoría eliasiana del ocio; (b) reflexión y elaboración del sentido del ocio para los indígenas optando por el neologismo alevezar (aligerar) como concepto que identifica tal sentido; c) selección de mapas para ilustrar los espacios de alevezar confeccionados por la estudiante indígena Martins (UFDG, 2011a) y (e) establecimiento de los criterios para sistematizar esos espacios asociándolos con las posibles actividades practicadas en ellos.

${ }^{11}$ La Constitución Brasileña de 1988, actualmente en vigor, preconiza el derecho a la diferencia y a la ciudadanía indígena rompiendo de este modo con la perspectiva histórica integracionista.

${ }^{12}$ Elias se refiere a los cambios conductuales de los individuos y la sociedad que tienen lugar lentamente y de forma integrada. En otras palabras, cambios en la organización estructural de la sociedad y cambios en la constitución psíquica individual. Los comportamientos ya incorporados en la persona y en la sociedad se denominan habitus.

${ }^{13}$ Desde una perspectiva eliasiana, los procesos civilizatorios "van constituyendo un habitus social de autocontrol de las emociones, de los afectos, de los sentimientos”. En este caso, serían procesos de conversión de la violencia física en violencia simbólica, circunstancia propia de los juegos (mímesis). 


\section{Tierra y territorialidad}

La mayor parte de las comunidades ${ }^{14}$ Kaiowá/Guaraní de MS ha estrechado relaciones con la población 'blanca'. La situación actual de esas comunidades es de 'confinamiento territorial', término acuñado por Brand (1993) al abordar el proceso de pérdida del control territorial en paralelo a la pérdida de autonomía política por parte de muchas de las aldeas. Confinados en áreas restringidas, esto es, en 'reservas' previamente demarcadas por el gobierno entre 1915 y 1928, permanecerán en esta situación a lo largo de casi todo el siglo XX.

El proceso de desposesión de las tierras indígenas se produjo en simultáneo con la ocupación de las mismas por población no-indígena y la ejecución de actividades agropecuarias a título particular. En esta figuración, la pérdida de los territorios tradicionales trajo como consecuencia la dispersión espacial y la fragmentación política de las comunidades. Otro factor reseñable fue el aumento de la especulación inmobiliaria si tenemos en cuenta que la reventa de las tierras a la población no-indígena suponía en muchas ocasiones la retirada de la propia población indígena (Pereira, 2009, 2010). La desestructuración del modo de vida también generó, según Pereira (2010), el agravamiento de problemas sociales como la violencia, la desnutrición infantil o los brotes epidémicos de suicidios ${ }^{15}$. La intensidad de tales problemas fue tal que terminarían por caracterizar globalmente a este pueblo. Los intentos de recuperar sus territorios por iniciativa de sus líderes tuvieron y tienen resultados positivos aunque se trate de un proceso lento y conflictivo. Todavía hoy la lucha por la tierra constituye el eje fundamental de los enfrentamientos Kaiowá/Guaraní con el Estado-nación y con las 'organizaciones no gubernamentales' que pretenden beneficiar a los propietarios particulares. Pese al apoyo de otros órganos no gubernamentales favorables a los indígenas o del propio poder público a través de una institución específica para asuntos indígenas - la Fundación Nacional del Indio (FUNAI) - el antropólogo Pereira (2010:133) considera que dichos órganos e instituciones "carecen de una metodología de trabajo que permita apoyar a las comunidades en la superación de las dificultades generadas por los procesos políticos de recomposición de las comunidades”.

En este terreno, aprehender el ocio significa no sólo alcanzar nuevas conquistas conforme a la Constitución de 1988, sino también comprender el nivel de

${ }^{14}$ En el presente artículo la expresión ‘comunidad' es empleada como sinónimo de la palabra 'aldea'. No queremos dejar pasar la ocasión de reseñar la existencia de investigaciones actualmente en curso a cargo de antropólogos indígenas que han acuñado la expresión ‘agrupamiento’ para designar las modalidades comunitarias Kaiowá/Guarani.

${ }^{15}$ Entre 1981 y el año 2000 se registraron 436 suicidios en reservas indígenas. A partir de 1990 este número aumentó de manera impactante alcanzando los 389 casos entre 1990 y el 2000. De entre estos 436, 225 son de personas entre los 12 y los 21 años, detectándose 91 casos en indígenas entre los 15 y los 18 años. Se trata, pues, de un fenómeno que afecta especialmente a los jóvenes, tal y como explican Brand e Vietta (2001:02). 
supervivencia de ese pueblo a fin de sistematizar sus espacios de ocio. Aunque alterados por los procesos históricos vividos, consideramos la responsabilidad política del ocio al mismo nivel que derechos sociales equivalentes como la educación, salud y vivienda, siempre de acuerdo con la especificidad de cada pueblo indígena (Brasil, 1988). Entendiendo el ocio de forma amplia y compleja, adoptamos la óptica eliasiana según la cual las disposiciones biológicas para el control de las emociones [impulsos] se activan gracias al aprendizaje sucediendo tanto de lo mismo con las disposiciones biológicas de liberación de tensiones y estrés: "Ambas son características resultantes de la evolución ${ }^{16}$ del nivel humano" (Elias, 1992:98)

La relevancia de este estudio radica, pues, en el esfuerzo en pos de una sistematización teórica que contribuya a un estudio profundizado de los Kaiowá/Guaraní que, a su vez, oriente a docentes e investigadores en la valoración de sus patrimonios culturales. Antaño, estos pueblos no necesitaban planificar el ocio. Hoy, realizar un 'proyecto de ocio' ya es una contingencia propia de los cambios sociales y culturales acaecidos. De hecho, el término 'ocio' cada vez se emplea con más frecuencia entre ellos.

Los indígenas que vienen a la ciudad pueden contemplar ese término en los carteles luminosos de las tiendas, en los anuncios de las empresas inmobiliarias, en las revistas o en los periódicos. También escuchan a los candidatos políticos realizar promesas de mejora en las ciudades y aldeas además de la programación en radio y televisión enalteciendo el ocio ${ }^{17}$ como medio de recuperación de niños y jóvenes en situación de riesgo/exclusión (Marcellino, 2005). Intensos en la lucha social, fuertes espiritualmente y frágiles en sus relaciones internas y externas, los Kaiowá/Guaraní albergan la esperanza de que el ocio contribuya a la transformación de la

${ }^{16}$ Evolución no como proceso lineal y biológico sino en el sentido de procesos continuos a largo plazo.

17 Dumazedier, citado por Marcellino (2005) afirma que existen ciertos elementos preponderantes en la búsqueda de actividades de ocio. Esta preponderancia conduce al individuo a priorizar determinadas actividades, lo que permite esbozar una panorámica didáctica de sus contenidos, que clasifican en seis áreas fundamentales: (1) intereses artísticos - orientados al imaginario, las imágenes, las emociones y los sentimientos, la estética, la belleza y el deslumbramiento; (2) intereses intelectuales - buscan el contacto con lo real, la información objetiva y la explicación racional, el conocimiento vivido, la participación en cursos y lecturas; (3) intereses físicos - engloban las prácticas deportivas, paseos, pesca, gimnasia y todas las actividades que suponen movimiento y ejercicio; (4) intereses manuales manipulación y transformación de materiales y objetos, artesanía, bricolaje, jardinería, cuidado de animales; (5) intereses sociales en el ocio - pretenden principalmente el establecimiento de relaciones entre personas en bailes, en bares como puntos de encuentro, los contactos cara a cara, las asociaciones; e (6) intereses turísticos - contacto con nuevas situaciones, paisajes, viajes y culturas diferentes. 
cotidianeidad, cuyo elemento central es la lucha por la tierra y la reinvención de su modo de ser.

Dialogar con los significados de la tierra y de la territorialidad para los Kaiowá/Guaraní requiere comprender, de acuerdo con Landa (2005:509), que ambos elementos están interrelacionados en sus "aspectos físicos, sociales, culturales y religiosos, aunque presenten diferencias entre ellos. La tierra es el soporte físico y el territorio es la posibilidad de vivir en plenitud el modo de ser Guaraní". La concepción de la tierra "en este momento histórico es el horizonte perseguido y, al mismo tiempo, la fuerza motriz que los moviliza para la acción y superación de las adversidades en su devenir”.

En el caso que aquí se estudia, la Reserva ${ }^{18}$ Indígena Francisco Horta Barbosa o Reserva de Dourados se halla a $15 \mathrm{~km}$ del área central del municipio de Dourados. Su interior lo atraviesa una carretera, la BR $156^{19}$, que conecta Dourados con el municipio de Itaporã, creada mediante el Decreto $n^{\circ}$ 401/1917 al amparo del Servicio $^{20}$ de Protección al Indio (SPI). A partir de 1970, la reserva fue dividida en dos partes: la aldea Jaguapiru y la aldea Bororó. Esta división fue solicitada por la propia comunidad ya que únicamente un capitán [líder político] no podía coordinar su funcionamiento conjunto debido al crecimiento de la población. La mayor parte de los habitantes habla el guaraní, aunque el portugués haya aumentado debido a las relaciones de trabajo y los contactos con el medio urbano.

Se organizan en 'familias extensas', término que traduce las figuraciones internas en redes de parentesco. Actualmente, la familia extensa pasa por cambios asociados a cuestiones de supervivencia y factores socio-económicos, circunstancia que empuja a los varones jóvenes y adultos al trabajo asalariado en el corte de la caña de azúcar, lo que a su vez les aleja del domicilio familiar un promedio de 20 días al mes o incluso meses enteros. De entre las diversas opciones de empleo existentes, en torno a unas 300 personas, de ambos sexos, trabajan en las escuelas de sus comunidades y algo menos actúa como agentes de salud. Con esa ampliación de los contactos, la vida cotidiana de la mayoría de las aldeas queda bajo la responsabilidad de mujeres y hombres que mantienen pequeñas rozas, cuidan de los niños, de los jóvenes, de los ancianos y de los animales domésticos en contextos diferenciados en función de la mayor o menor dimensión de los conflictos asociados a la situación jurídica de las tierras que ocupan y de la mayor o menor proximidad a los centros urbanos.

El proceso ininterrumpido de ampliación de la red de interrelaciones llevó a los Kaiowá/Guaraní a estructurarse con arreglo a un núcleo identitario que fortalece las negociaciones necesarias para restablecer el equilibrio de poder en las relaciones

${ }^{18}$ Tierra Indígena y Reserva se usan de forma equivalente en estas páginas.

${ }^{19}$ En torno a 1950 se inició la tala para su construcción.

${ }^{20}$ Uno de los primeros órganos gubernamentales brasileños destinados a atender al sector indígena, fue reemplazado por la FUNAI. 
con el Estado. Hacen valer las diferencias imponiéndose a través de los medios de comunicación o de las redes sociales produciendo vídeos, organizando visitas que muestran sus precarias condiciones de existencia o promoviendo la recuperación de la tierra. La mayoría de sus conquistas está vinculada a los movimientos sociales de ámbito nacional e internacional.

De esa forma, para abordar el ocio, seguimos la trilogía (i) tierra o tekoha, enclave geográfico transformado por la cultura y pleno de significados que pasa a denominarse territorialidad; (ii) cultura o teko, constituida por valores y prácticas continuamente permeadas por la espiritualidad y (iii) lengua guaraní o ñe'ë, responsable de la traducción de las 'bellas palabras ${ }^{21}$, en fuerza política interna de cohesión grupal. Esta trilogía se articula en el llamado ñande reko, término alusivo a "nuestra vida" o "nuestra forma de ser y vivir según nuestras costumbres y tradiciones". Estas tres instancias de relaciones de poder internas son constitutivas de sus identidades (UFGD, 2010)

Los Kaiowá/Guaraní poseen saberes que han de ser transmitidos internamente con miras a mantener la tradición en paralelo a la dinámica de las redes de interrelaciones establecidas con el no-indígena, con otras etnias y con las nuevas tecnologías de la información y la comunicación (TICs). La tradición se entiende aquí, en sentido eliasiano, como un 'efecto de freno' por aminorar los cambios no significativos para el grupo. Ello supone una forma de 'resistencia' frente a las tensiones transformadoras adyacentes a las negociaciones y enfrentamientos procedentes de las relaciones externas e internas (Elias, 1980). En este sentido de cambios y re-significaciones, Gallois (2006:20) sostiene que "lo tradicional en el saber tradicional no es su antigüedad sino la manera como es adquirido y usado" continuamente en la producción de conocimientos. La autora se refiere principalmente a la preservación, renovación y/o desuso de sus patrimonios culturales inmateriales. Ambas visiones ayudan a dilucidar el modo de ser Kaiowá/Guaraní y sus diversas maneras de resistencia, de selección y, dentro de lo factible, también de aislamiento en sus propios universos.

Son esas referencias étnicas las que permean y están en la base de las reflexiones sobre el ocio. Entendiendo el ocio en su conexión con las emociones, adoptamos al respecto el enfoque propuesto por Elias y Dunning (1992). Según dicho enfoque, las transformaciones del ocio no están planeadas y resultan de figuraciones sociales a largo plazo que se basan en tres aspectos fundamentales. El primero se refiere al ocio como efecto histórico específico que afecta a las relaciones de equilibrio y de restricción [aprendizajes, tensiones y estrés en múltiples esferas, ya sea frente al modo de vida tribal, ya sea frente a la complejidad de los modos de vida urbanos]. El segundo alude al ocio como el acto de descartar las emociones violentas, espontáneas e intensas - otrora comunes en sociedades de organización simple cuya

${ }^{21}$ El pueblo guaraní es conocido por la fuerza del verbo, de la palabra. 
'red de relaciones cortas $^{22}$, favorecía el carácter espontáneo de la emocionalidad hoy sometidas a normas y restricciones sociales y psicológicas construidas en procesos de larga duración y en una 'red de relaciones ampliadas'. El tercer y último aspecto entiende que el ocio actual se corresponde de forma creciente con formas de comportamientos miméticos, esto es, formas de diversión que permiten emociones intensas pero controladas mediante normas y coacciones rigurosas tanto a nivel individual como colectivo (Elias, 1992:98)

Abramos a continuación un paréntesis para retomar el segundo aspecto antes citado y recuperemos para ello una advertencia que ya Elias (1998:23) realizó en su momento. Existe el riesgo de que establezcamos una relación directa entre los grados más o menos elevados de autodisciplina en relación al tiempo social. La cuestión clave es nuestra fragilidad en cuanto a las oportunidades de supervivencia del ser humano, tanto individual como colectivamente, en el caso de que no se desarrolle nuestro potencial de autodisciplinamiento. Desde pequeños aprendemos a sobrevivir frente a la exteriorización de las pulsiones e impulsos afectivos, ora en lo individual, ora en lo comunitario. Lo que se modifica en el largo plazo de un proceso civilizador son los distintos tipos de auto-regulaciones y el modo en el que están integradas. Si no se tiene en cuenta esto, "la noción de proceso civilizatorio resulta frecuentemente vulgarizada”. Por ejemplo, tal noción se presenta de forma reduccionista cuando se acepta que existe un crecimiento constante de las restricciones que cada individuo se impone a sí mismo. Este modo de comprender el proceso civilizatorio sugiere que las autocoacciones en las sociedades más simples [menos complejas] serían uniformemente débiles o estarían ausentes, y la expresión o descarga de afectos y pulsiones sería uniformemente intensa en todas las áreas de la vida. Lo cierto, destaca Elias, es que las restricciones varían con frecuencia. Hay situaciones dentro de sociedades simples en las que las modalidades de autodisciplina son más rigurosas que en las sociedades complejas. $\mathrm{Y}$ existen otras situaciones que exigen descargas afectivas y pulsionales que alimentan conductas violentas y espontáneas inaceptables en sociedades complejas. Las restricciones hetero-impuestas $\mathrm{y}$ las auto-impuestas son diferentes "simplemente por el hecho de que al situarse la conciencia en un mundo poblado de espíritus omnipresentes, esto afecta de manera sistemática a la conducta y a la sensibilidad de los hombres" (Elias, 1998:24). En ese sentido, sin una frontera claramente trazada entre seres animados e inanimados puede prevalecer una voluntad sobrenatural relacionada con algún ente u objeto. Como esos símbolos representan funciones de orientación y regulación, no es sencillo decidir si las coacciones que ejercen son de orden interno o externo.

${ }^{22}$ Red de interrelaciones restringida a una pequeña población. 


\section{Tiempo, espacio y ocio}

Retomando el diálogo con la visión particularizada del universo indígena Kaiowá/Guaraní, cabría aplicar los aspectos del ocio distinguidos por Elias del siguiente modo: el primer aspecto del ocio interligado a las emociones se relaciona con la realidad actual de los Kaiowá/Guaraní en el sentido de que hoy las tensiones generadas por el mundo urbano sobre sus tierras y tradiciones así como la presencia del Estado Nacional dividiendo el poder con líderes locales, caciques ${ }^{23}$ y jefes espirituales producen conflictos desequilibrando e introduciendo restricciones extrañas al modo de vida de la aldea. El segundo aspecto remite a la forma de liberar tensiones. Teniendo en cuenta la ampliación de la red de interrelaciones, esas tensiones eran antes más libres e intensas oscilando entre extremos de alegría y tristeza y estaban restringidas a grupos familiares o colectivos pequeños mientras hoy se exige cada vez más autocontrol. Relativamente al tercer aspecto, el estudio de Vinha y Rossato (2009) identifica una creciente forma de ocio entre los indígenas en la que predominan las actividades deportivas - por tanto, de carácter mimético - procedentes de mayores niveles de autocontrol y de nuevas reorganizaciones sociales.

Las interrelaciones fruto del ocio son mediadas por la cultura Kaiowá/Guaraní. Las relaciones emergen cuando promueven reflexiones sobre el comportamiento, aportan información, fortalecen los lazos de cooperación, revitalizan valores y aquilatan los modos de ser (Elias, 1980). Un modo de vida tribal en el que las mayores catástrofes suelen ser la pérdida de la cosecha, la necesidad de mudar de región y abandonar las casas o alguna epidemia terminó por alterarse. Y así, con el pasar del tiempo, la población se fijó territorialmente y sedentarizó en espacios delimitados por el Estado de acuerdo con imperativos de orden geográfico y político (Pereira, 2010). A pesar de estos cambios, el modo de ser Kaiowá/Guaraní se nutre de un patrimonio cultural que se expresa mediante diferentes manifestaciones orales y visuales presentes en la memoria de sus ancianos. Esa inmaterialidad, el núcleo de la identidad, se mantiene en la dinámica espaciotemporal del grupo. En diálogo con ellas o asimilándolas sin llegar verdaderamente a comprenderlas, viven expuestos a la tensión de las nuevas interrelaciones. Con todo, en el caso de las "redes de relaciones históricas y de procesos seculares de intercambio", muchos elementos culturales son compartidos por pueblos de la misma región. Al compartir, amplían sus redes y reelaboran esos elementos en sus contextos específicos "permitiendo a cada grupo reconocer y valorar lo que considera parte de su propio patrimonio cultural”, tal y como apunta Gallois (2006:7).

${ }^{23}$ Para los Kaiowá/Guarani, cacique es sinónimo de "rezador”; no es, por tanto, un líder político. 
A día de hoy, los Kaiowá/Guaraní viven en condiciones de interdependencia cada vez más estrecha con la organización estatal además de contar con la efervescencia de sus propias relaciones internas, de sus propios valores y de sus tradiciones sometidas a una dinámica nunca vista. Ante estos hechos, queremos destacar que este estudio no pretende obtener respuestas definitivas y cerradas. Antes bien tan sólo pretende mostrar lo mucho que tenemos que aprender de nuestro papel como co-participantes en un proceso a largo plazo.

Así, la reflexión sobre el ocio entre los Kaiowá/Guaraní reenvía a temas como el tiempo y el espacio. Hay estudios que asocian el tiempo al trabajo, otros que disocian el tiempo del ocio, algunos atribuyen al tiempo ocioso el desarrollo intelectual. Son muchas las teorías y éstas no constituyen una prioridad para este artículo. Para los Kaiowá/Guaraní, el tiempo y el espacio se traducen como ara, expresión guaraní que aúna inseparablemente el tiempo y el espacio: una sola palabra que sintetiza dos sentidos socialmente construidos.

Nuestra reflexión sobre la síntesis tiempo-espacio [ara] se basa en Elias (1980) y su sociología figuracional ${ }^{24}$. Según ésta, en estadios anteriores de la humanidad, un grupo humano desprovisto de conceptos sobre la complejidad del tiempo elaboraba únicamente una síntesis reducida y local sobre ese fenómeno social construido por humanos. Por eso, la expresión única de la lengua Kaiowá/Guaraní se presenta discontinua y polarizada tal y como veremos a continuación.

Estudios sobre el pueblo Mbyá ${ }^{25}$, uno de los componentes del gran pueblo Guaraní, indican que para ellos el tiempo está categorizado como 'tiempo instituyente' y 'tiempo instituido' (Borges, 2002). 'Tiempo instituyente' se refiere al tiempo primario que se estructura y funciona en el imaginario de todas las sociedades teniendo como base el tiempo cósmico. 'Tiempo instituido' se refiere al lugar socialmente producido que enmarca la cotidianeidad de la sociedad y sus sujetos. En la relación entre tiempo y espacio Mbyá, el espacio es el lugar de las cosas pudiendo también ser concebido con una multiplicidad simultánea y, por lo tanto, como diferencia. En esa misma relación, el tiempo es la dimensión del movimiento y de la duración. De nuevo, puede entenderse además como una multiplicidad sucesiva y, en consecuencia, como diferencia.

El tiempo, lugar de alteridad y exterioridad, participa de la construcción del proceso socio-histórico Mbyá en cuanto la intensa espiritualidad guaraní se erige como núcleo fundador de su ethos, condición de su sostenibilidad ${ }^{26}$ cultural. El orden cosmológico, es decir, el 'tiempo instituyente', es el fundamento del modo de ser de este pueblo. La forma en la que representan el 'tiempo instituido' [orden

${ }^{24}$ Abordaje que asume la indisociabilidad de sociedad e individuo. En este sentido, sugerimos la lectura de "La Sociedad de los Individuos" de Norbert Elias.

${ }^{25}$ Mbya es una las partes de la nación Guaraní que vive en el litoral brasileño.

${ }^{26}$ En el sentido amplio del término, la sostenibilidad está relacionada con la cosmología y la cultura yendo más allá de proyectos sociales de índole económica o social. 
socio-histórico] se encuentra subsumida en el orden cosmológico [tiempo instituyente]. Así, Borges (2002:114) explica que los marcadores celestes [astros], estacionales [floración, plantación] y rituales [cosechas, fiestas, bautizos] siguen teniendo hoy una función totalizante del tiempo estableciendo un orden en la transitoriedad de las cosas. Ara es, por tanto, una unidad espacio-temporal en la que la indivisibilidad entre tiempo y espacio emerge por obra de la intervención directa de Ñanderu [creador] y no como un acto de voluntad personal o social. Según esa condición, tiempo y espacio de ocio Kaiowá/Guaraní sería el 'tiempo instituido' [socio-histórico] guiado por el 'tiempo instituyente' [cosmológico].

Regresando a nuestro diálogo con Elias $^{27}$ (1980:76-78) y desde una perspectiva a largo plazo, tres aspectos sobre el tiempo encuadran nuestras reflexiones.

El primero alude a la singularidad del patrón de medida utilizado para determinar posiciones e intervalos en el interior de aquello que llamamos 'tiempo'; patrón distinto al que empleamos cuando nos referimos al 'espacio'. Esa diferencia dificulta la elaboración de normas y de conceptos temporales así como la formulación clara de preguntas del tipo “¿cuándo?”, cuya resolución depende de esas normas y conceptos. Los físicos entienden esa diferencia, afirma Elias, mas en nuestra tradición intelectual existe la tendencia a ocultar ese proceso de continuos evolutivos en sistemas aislados que oscurecen la naturaleza del tiempo.

El segundo aspecto de la naturaleza del tiempo es el relativo a la determinación del propio tiempo, desde una forma discontinua y situacional a una trama temporal continua y pormenorizada que encierra y condiciona en su universalidad la extensión total de las actividades humanas. Hoy, las redes sociales de los países industrializados son de ese tipo. Se trata de redes que se extienden progresivamente por todo el globo de tal manera que en aquellos lugares en los que la forma de determinar el tiempo es más restringida, hay dificultades para adoptar esa vivencia del tiempo como trama continua. Elias (1998:77-78) da como ejemplo el de una mujer sudamericana que, al regresar de un viaje a Alemania, señalaba cómo los relojes alemanes de las estaciones de ferrocarril tenían tres punteros: el de las horas, los minutos y los segundos. Y los tres eran necesarios pues el horario de los trenes era preciso y secuenciado. Este tipo de observaciones nos ayuda a agudizar nuestra percepción de cara a un análisis más completo de la síntesis subyacente a las experiencias del tiempo y las instituciones relacionadas con el mismo. Sin embargo,

${ }^{27}$ Elias propone una limpieza conceptual como punto de partida en el estudio del tiempo, tal y como puede apreciarse en su libro "Sobre el tiempo". El autor sostiene que ciertos postulados sobre este tema se hallan profundamente enraizados en nuestras expresiones y pensamientos sin que resulten cuestionados o modificados. Admite que una tarea de este porte no es asumible para un solo individuo al no disponer del poder necesario para substraerse a los instrumentos de orientación de una sociedad o a los axiomas temporales asumidos como correctos. De igual modo, tampoco dispondría del suficiente conocimiento o de la longevidad necesaria para una iniciativa de este calibre. Al respecto, véase Elias (1998:76-78). 
el reloj no es el tiempo y sí un instrumento más para su medición, como lo fuera en su día el ciclo del sol. Para resolver el enigma del tiempo éste debe ser revisado como concepto así como las diversas unidades temporales (año ${ }^{28}$, hora, minuto) "todas las cuales indican intervalos estandarizados que se repiten entre una posición anterior y una posterior de una unidad de cambio" La operación de determinar el tiempo representa una manera específica de conectar los acontecimientos o de operar una síntesis de esos acontecimientos (Elias, 1998:75). Actualmente es habitual que asumamos esa síntesis del aspecto temporal de los acontecimientos como algo común y espontáneo [orden cosmológico]. Tanto las síntesis que provienen de nuestra experiencia como aquellas que consideramos dadas de antemano, las que son previas a esa experiencia, no suelen ser entendidas como una construcción social: es complicado que lleguemos a tomar conciencia de este hecho, de esta construcción que se fue elaborando con el transcurrir del tiempo y que trajo consigo formas de relacionarse con reglas temporales.

Elias (1998:10), al teorizar sobre el tiempo desde la óptica de la sociología figuracional, sostiene que la comprensión del mismo se apoya en procesos de aprendizaje que no poseen un punto de arranque datado con exactitud en la historia de la humanidad. Cualquier persona va construyendo su conocimiento a lo largo de un proceso y a partir de un patrimonio de saber ya adquirido en sociedad al cual contribuye en el sentido de aumentarlo. El autor insiste en que el tiempo "forma parte de los símbolos que los hombres son capaces de aprender y con los que, en ciertas etapas de la evolución, están obligados a familiarizarse como medios de orientación”. Mientras la lengua de un grupo resulta de un largo proceso humano de autorregulación individual de los hablantes, "la autorregulación en relación a una cronología sólo se instauró progresivamente a lo largo de la evolución humana. Y fue en una etapa relativamente tardía cuando el 'tiempo' se convirtió en una coacción universal e ineluctable” (Elias, 1998:20-21).

Por lo tanto, ¡nada hay de espontáneo! Nosotros, los humanos de diversos periodos socio-históricos anteriores no teníamos medios para saber cómo se concatenan los acontecimientos 'en el tiempo'. Fue necesario un esfuerzo continuado y doloroso para poder llegar al estadio actual; un estadio que es la síntesis que engloba el amplio conjunto de síntesis de nuestros ancestros. La síntesis sobre el tiempo de la que nos hemos apropiado representa exclusivamente una etapa tardía de un proceso sumamente largo, apunta Elias (1998:78).

${ }^{28}$ Carlos IX, rey de Francia, decidió en 1563 imponer una fecha única, el 1 de Enero, como inicio del año. La decisión entró en vigor en 1566 acabando con la tradición que hacía nacer el año con la festividad de la Pascua. Así, el año 1566 comenzó el 14 de Abril y finalizó el 31 de Diciembre, contando con un total de 8 meses y 17 días. Este ejemplo lo presenta Elias (1998:46) para ilustrar la construcción histórica del tiempo y mostrar las diferencias en relación a su medición actual en los países occidentales. 
El tercer aspecto alude a la relación entre 'naturaleza' y 'sociedad'. La distinción naturaleza-sociedad es/fue vista como un axioma que fragmenta esos dos elementos humanos, circunstancia que afecta a la problemática del tiempo. De esa forma, el tiempo físico sería distinto del tiempo social y del tiempo vivido. Ejemplos extraídos de sociedades más simples muestran cómo la determinación del tiempo reposa en la asociación, por un lado, de lo natural o lo físico [tiempo instituyente] y, por otro, de lo social o humano [tiempo instituido] con secuencias de acontecimientos ajenas entre ambas partes.

En nuestro intento de comprender el contexto del tiempo para los Kaiowá/Guaraní, mantuvimos un primer diálogo con los alumnos indígenas que estudian la Licenciatura Intercultural Indígena Teko Arandu. ¿Cómo comprendían el ara [tiempo-espacio] enfatizando el esparcimiento, la recreación y el ocio? Estos tres términos - esparcimiento, recreación y ocio - eran usados cotidianamente por los alumnos cuando nos pedían un balón o solicitaban la organización de una fiesta para 'recrearse' o por 'ocio'. Así, aproximadamente 50 alumnos debatieron en lengua guaraní los temas propuestos para después abrir la cuestión al diálogo bilingüe.

Sobre el 'esparcimiento' destacaron que se asociaba a la pereza. Incluso resultaron estigmatizados por esa atribución peyorativa que hace de los indígenas unos "perezosos" que viven en el esparcimiento. Todavía hoy es un tema recurrente en sus conversaciones cuando se recuperan las historias sobre la colonización. La pereza, desde el punto de vista del colonizador, se aplica a la falta de voluntad para trabajar en tiempos y espacios determinados. Sin embargo, la misma expresión se utiliza entre los Kaiowá/Guaraní para la pareja de recién casados que se muestra perezosa al encontrarse al 'final de sus fuerzas' [de amarse tanto] o cuando alguien va a jugar un partido de fútbol y llega tarde. Una de las alumnas complementó la explicación sobre el esparcimiento del siguiente modo:

En el pasado, el término esparcimiento lo usaba el no-indígena para explicar el modo de vida de indígena de (aparentemente) no hacer nada [...] No obstante, los cambios que llegaron con las relaciones de contacto transformaron la forma de vida tradicional y llegaron el trabajo asalariado, la jubilación, la disminución del trabajo en la roza y la dependencia de la cesta básica. También llegó el reloj, el móvil, la televisión, el DVD y más cosas. Y esta transformación alteró totalmente el modo de vida de nuestros niños y jóvenes. Cambiaron las formas habituales de ocio entre padres e hijos; por ejemplo: bañarse en el río, pescar, cazar, recoger frutos, hacer trampas, buscar material para artesanía, entrenamiento con el arco y la flecha, plantar, recolectar y otras cosas que forman parte de la educación indígena. (El paréntesis es un añadido nuestro)

Sobre 'recreación' respondieron que se trataba de [...] juego, lugar de diversión, barullo, expresión, juegos orientados a buscar alguna cosa o de alevezar (aligerar) el cuerpo. Sobre el 'ocio' se dijo que era lo desatado, lo suelto, alegrarse, el sitio de juegos, las bromas, la espontaneidad, el estar en movimiento o "eléctrico" (UFGD, 2009). En esta línea, algunos alumnos llegaron a afirmar que el indígena kaiowá/guaraní no necesita estudiar ocio pues eso era algo que se aprendía de forma 
natural en el pasado. Entendemos que una afirmación de esta naturaleza tiene sentido aunque nos intrigase dada la posibilidad que ofrece el derecho constitucional del reconocimiento de la diferencia así como la importancia de las actuales transformaciones socioeconómicas de sus mundos étnicos.

Tener tiempo para pensar, para expresarse, para ser espontáneo; sitio de juegos, de diversión, de lo que no es hecho; no hacer nada, aligerar el cuerpo y estar en movimiento fueron los significados más citados a la hora de definir los tres términos. Las respuestas fueron unánimes a la hora de dejar de lado el trabajo, incluso entendido como rutina de supervivencia en las aldeas. El neologismo alevezar (aligerar), ha sido acuñado por Vinha y Rossato (2009) al entenderse que resulta el más apropiado para definir la liberación del ocio respecto del dualismo trabajo/ocio y para mantenerlo al margen del eje de tensiones compensatorias propias de la sociedad urbanizada.

En el diccionario Houaiss (2007) no existen registros para este neologismo. En consecuencia, las autoras optamos por buscar en 'leveza' (ligereza) y 'leve (ligero) + eza' significados etimológicos relativamente comunes como 'frescor (frescor)', 'delicado (delicado)' y 'singelo (simple)', lo que permitió asociarlos con el estado ideal de comportamiento y/o sentimiento kaiowá/guaraní: no ser violento, arrogante, caliente, duro, intransigente, malhumorado o impaciente. Alevezar (aligerar) amplía su significado al indicar la profunda ligazón con el mundo espiritual pudiendo también asociarse a una de las grandes metas de los "rezadores", los ñanderu, quienes practican oraciones, danzas rituales y dietas alimenticias durante varios días para de este modo alevezar (aligerar) el cuerpo hasta el punto de auto-transportarse al 'cielo' - como relató Paulito Aquino a Rossato en 1993.

Vinha y Rossato (2009) explican que alevezar (aligerar) remite asimismo a ' $\operatorname{lev}(\mathrm{i})$ ', un lexema utilizado en varias lenguas con diferentes sentidos entre los que destacan: levantar, elevar, descargar y aliviar. El añadido del prefijo 'a' al verbo puede significar 'transformar en', 'hacer' o 'causar'. Así 'a+leveza+r' = volverse hacerse leve. ${ }^{29}$

Tiempo y espacio Kaiowá/Guaraní fueron también objeto de reflexión por parte de uno de los 'caciques' / 'rezadores'a la hora de valorar la interculturalidad actuando como 'maestro tradicional' durante las clases de la Licenciatura Indígena/ (UFGD). Actualmente, explicó el anciano, de entre las tensiones que afectan a los indígenas, existe la violencia y esta, en muchas ocasiones, genera suicidios. También se refirió al hecho de que los niños no obedecen a sus padres y que por ello puede hablarse de una crisis de autoridad. Si la madre regaña y corrige el niño, se molesta y se 'pierde'; empieza a 'caminar sin rumbo'. Según él, ya no hay

${ }^{29}$ Otros ejemplos como 'amalucar' = 'volverse maluco [loco]'; 'Amansar' = volverse manso'; 'acalmar' = 'calmarse’ pueden explicarse a partir del dicionário Larousse Cultural (1992). 
adhesión al ñande reko [trilogía tekohá, teko y ñe’e] como modo de ser: sería necesario aglutinar a los Kaiowá/Guaraní en torno al pensamiento, los significados y los valores que les confieren identidad.

Las palabras del 'cacique' resultaron contundentes y nos alertaron sobre su perspectiva acerca de cómo comunicarse para invertir el ñemboy avy [desequilibrio, malentendido, equívoco, error]. Finalizó su intervención apelando a la espiritualidad, lo que remite de nuevo a la intensa religiosidad guaraní, condición de sostenibilidad cultural de este pueblo. Sostuvo que antes los niños nacían y con el bautismo [ñemongarai] sabían lo que habrían de ser en el futuro. Hoy, las familias no valoran el bautismo y, de acuerdo con sus palabras, la persona que muere no va 'hacia el dios' sino que permanece vagando. Si los niños vienen al mundo con esa debilidad, la persona que fallece termina por coaccionar a quien está vivo y éste acaba por morir. Vaticinando de esta forma el destino de algunos individuos de su pueblo, el "rezador" buscó en el tiempo instituyente [tiempo cosmológico] lo que para nosotros puede ser comprendido como la ampliación de la red de interrelaciones [tiempo instituido]

Otra reflexión, esta vez de una de las profesoras-alumnas ${ }^{30}$, evidenció que el uso del tiempo en las comunidades indígenas con poca tierra disponible ha traído consigo, en primer lugar, la desestructuración del modo de vida debido al hacinamiento de las familias extensas y la disminución de los espacios físicos entre ellas. Esa falta de espacio disociada del tiempo [ara] fomenta los contactos cotidianos con personas ajenas a la familia generando conflictos. En este sentido, aludía al aumento de los "cotilleos" o a la ausencia de espacio para criar gallinas, para distraerse con lo que el tekoha ofrece natural y socialmente, para no hacer nada o para "refrescar" la cabeza o mantenerse "frío" [estado ideal de los Kaiowá/Guaraní]. El estado de no-rabia, no-nervios, no-violencia, esto es, la imposibilidad de alevezar (aligerar) comporta también hambre y violencia. El suicidio, como apuntaba el "rezador", provendría de esa violenta desorganización del espacio-tiempo. Sabiamente, el "rezador" percibe correctamente que no es el tiempo el que pasa, sino que ese paso se refiere al curso de su propia vida y de su pueblo, así como a las transformaciones de la naturaleza y de la sociedad (Elias, 1998:22)

\section{Espacios de ocio registrados por los indígenas}

Tierra, territorio y territorialidad pueden sintetizarse para los Kaiowá/Guaraní como tekoha, es decir, el lugar, el modo de vida, la lengua y la cultura. Nuestras reflexiones vienen guiadas por cierta problematización de las interrelaciones entre

${ }^{30}$ La licenciatura en su nivel superior prioriza la formación de indígenas que ya actúan como profesores en sus aldeas. 
tekoha y ocio. El ocio, para los Kaiowá/Guaraní, depende del tekoha y del teko, de la lucha liderada por profesores, la cual puede tener en el ocio un medio, un instrumento. Valores corporales contemporáneos mediados por la 'industria cultural' o la corporeidad kaiowá/guaraní son temas todavía no abordados. El ocio estaría, pues, dentro de una red temática de sistema abierto puesto que a través de este concepto pueden desarrollarse varias cuestiones manteniendo lo lúdico en la triangulación diversión-descanso-transformación tal y como indica Dumazedier (citado en Marcellino, 2005). Sugerimos a los alumnos indígenas una actividad de investigación durante el periodo curricular en el que los profesores universitarios van a las aldeas: confeccionar mapas en los que indicasen los espacios de ocio en sus aldeas a fin de tener una primera identificación de esos espacios lúdicos. De los aproximadamente 25 mapas, hemos seleccionado para este trabajo el de la Reserva de Dourados, realizado por la alumna indígena Raica Martins (UFGD, 2011).

Para identificar los espacios de ocio empleamos la ilustración número 1, realizada por Martins, como una síntesis del resto de las ilustraciones. Hemos rodeado con un círculo discontinuo los espacios de cariz deportivo basándonos en Elias y su idea de que el predominio de tales espacios sugiere una percepción sistematizada y diferenciada en relación al tiempo. En consecuencia, nos basamos en las relaciones de juegos deportivos, las cuales pueden estar extendiéndose a otras áreas de relación social cuyos equilibrios de poder pudieran estar sometidos a cambios. La capacidad de los actuales Kaiowá/Guarani para someterse a nuevas restricciones autoimponiéndose controles - personales y colectivos- más intensos es muy significativa.

El mapa mostró 13 espacios/modalidades deportivas, con predominio del campo de

Ilustración 1: Mapa de los espacios de ocio de la aldea Bororó y Jaguapiru, con círculos en los que se destacan los espacios deportivizados (UFGD: 2011a).

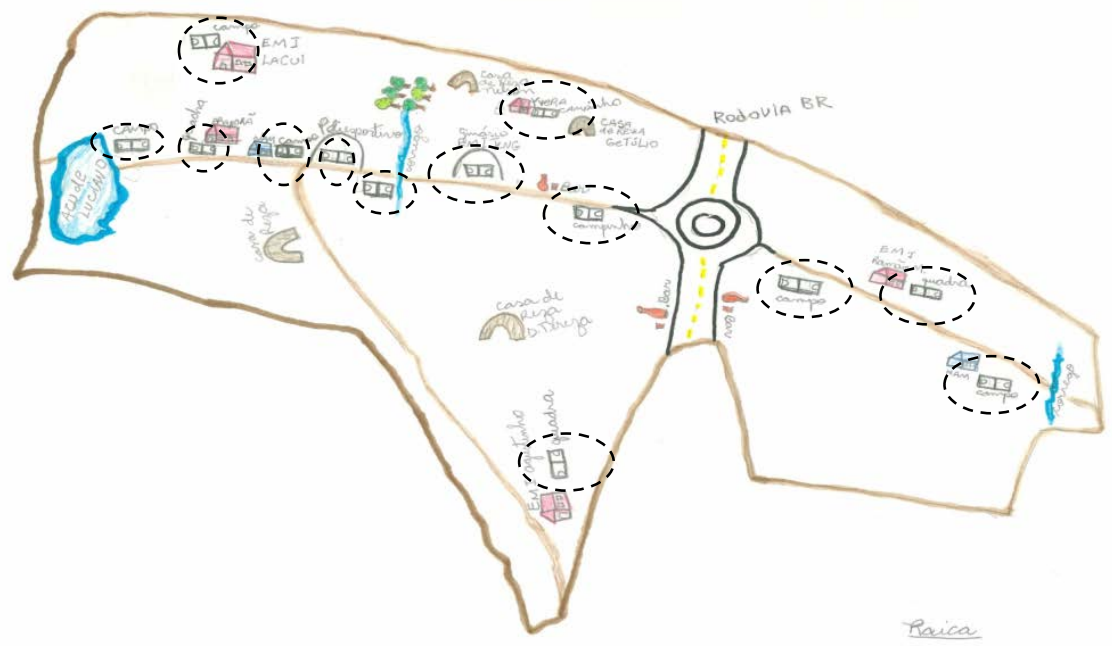


fútbol y de canchas polideportivas (las canchas situadas en las escuelas se incluyen en este caso): diez de estos espacios están en la aldea Bororó y 3 en la aldea Jaguapiru; 3 espacios/agua para actividades de pesca, baños y juegos, 2 de ellos en la aldea Bororó y 1 en la Jaguapiru; 3 espacios/caminos vecinales de tierra (2 en Bororó y 1 en Jaguapiru) que se recorren a pie, en bicicleta, a caballo o en carro; 5 espacios escolares con equipamiento recreativo como toboganes y columpios (2 en Bororó y 1 en Jaguapiru); 1 espacio/selva; 4 espacios/Casa de Rezos o casa de la cultura, empleada para rituales y algunas actividades lúdicas; 3 espacios/bar en los que se venden comida y bebida. No se contabilizan los ambientes familiares en los que también pueden llevarse a cabo actividades lúdicas.

Cuadro 1: Síntesis de los espacios de ocio de la Reserva Francisco Horta Barbosa, Dourados/MS

\begin{tabular}{|c|c|c|c|c|c|c|c|}
\hline Aldeas & 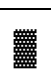 & ! & 引 & () & \& & $\boldsymbol{\Delta}$ & g \\
\hline 1. Bororó & 10 & 02 & 02 & 04 & 01 & 03 & 02 \\
\hline 2. Jaguapiru & 03 & 01 & 01 & 01 & -- & -- & 01 \\
\hline Total & 13 & 03 & 03 & 05 & 01 & 03 & 03 \\
\hline
\end{tabular}

Leyendas:

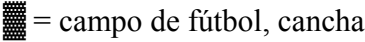

polideportiva

i = dique, corriente

$\downarrow$ t $=$ camino, carretera

() = escuela

s = selva

$\boldsymbol{\Delta}=$ casa de rezos, casa de la cultura

l $=$ bar

Rocha Ferreira et al (2005) ${ }^{31}$ organizaron una comparación entre las propiedades estructurales de los juegos populares y los juegos deportivizados. El 'juego popular' presenta una organización informal implícita en la cultura local, con sus reglas simples y orales y con diferencias en las mismas conforme a zonas o regiones, con variaciones en el tamaño del balón, del campo o del número de jugadores. Existe poca diferenciación en la división de tareas entre jugadores y un control social informal dentro del contexto de juego que incluye emociones más espontáneas y abiertas al placer y una relativa igualdad en la habilidad motriz de los jugadores. Por su parte, el 'juego tradicional' mantiene características similares a las del popular, con la diferencia de que puede incluir manifestaciones de la cultura corporal con significados rituales practicados como pre-requisitos para cambios en

${ }^{31}$ Inspirándose en Elias \& Dunning (1992), Rocha Ferreira et al establecen una distinción conceptual entre juego popular y juego tradicional, atribuyendo a éste último elementos y vínculos de la cosmología de cada pueblo. 
la posición social, para celebrar eventos de la naturaleza o para homenajear a seres sobrenaturales.

El 'juego deportivizado' se estudia como un fenómeno de la actualidad y su desarrollo puede explicarse a partir de diferentes enfoques socio-antropológicos. Elias y Dunning (1992) afirman que los primeros deportes tuvieron su origen en juegos tradicionales europeos a pesar de que hoy se sigan creando modalidades sin ese tipo de vínculo socio-cultural. De entre las propiedades estructurales del deporte es necesario considerar la propia transformación del ‘juego popular y tradicional' en deporte, ligada a la trayectoria de transformación del Estado-nación. Procesualmente, esos juegos-deportes tuvieron sus reglas institucionalizadas y burocratizadas a través de canales formales. La práctica de deporte pasó a desarrollarse en espacios limitados y con un número fijo de jugadores de funciones diferenciadas y las reglas pasaron a ejercer un control formal de las faltas llevando aparejado un bajo nivel de tolerancia a la violencia física. Todo ello exigió de los jugadores más control emocional que el que exigían los juegos populares y tradicionales locales.

No obstante, estudios recientes realizados en Brasil sobre los juegos de los pueblos indígenas apuntan a que, aunque las modalidades deportivas [individuales y colectivas] estén regidas por normas e instituciones deportivas internacionales, existe un diálogo entre esas reglas y algunos elementos culturales propios de cada pueblo indígena. Al interrelacionar 'juego tradicional y popular' y 'juego deporte' nos encontramos con la expresión 'etno-deporte’. Según Fassheber (2006:91), el etno-deporte comprende "procesos dinámicos de transformaciones por las que pasan los juegos tradicionales indígenas y la introducción de deportes modernos en la mayoría de las TIs brasileñas [...] que reflejan un tiempo pasado que coexiste con el presente”. Así, el etno-deporte indígena, en Brasil, está "fundamentado en la posibilidad de que las culturas adapten y transformen sus propias tradiciones y que se adapten y se transformen en función de las tradiciones que proceden del contacto". Ese movimiento, explica el autor, expresa también el "proceso de resignificación de los valores culturales y una re-inserción en el mundo de los blancos (2006:91)

La resignificación tiene lugar simultáneamente bajo las coacciones de la sociedad de origen, del fuero íntimo personal [latentes durante cualquier juego popular, tradicional o deportivo] y de las nuevas redes de contacto. El modo de ser durante el juego tradicional se basa en las reglas [habitus] establecidas en cada sociedad que creó, adoptó y practica ese juego y está conectado a la producción, reproducción o renovación de valores y saberes. También depende de formas diferenciadas de poder, vigentes en cada sociedad, así como del habitus relacionado con el género, la ideología y la identidad. En muchas ocasiones, cuando el juego tradicional también es ceremonial al evocar una conexión mitológica entre los participantes, las coacciones son de carácter sobrenatural, tal y como explican Rocha Ferreira et al. (2005).

Estas son sólo reflexiones iniciales y, en consecuencia, estudios más detallados deberán aportar más conocimiento sobre el proceso de transformación del tiempo- 
espacio enfatizando la teorización del tiempo kaiowá/guaraní asociado al espacio [tierra, territorio] y problematizando la territorialidad ligada al ocio, a las relaciones del juego y sus repercusiones sobre el modo de ser. Para reafirmar nuestra argumentación, uno de los estudiantes indígenas, en una de las clases presenciales en el campus de la universidad afirmó: "Hoy, al estudiar, siento que el estudio acostumbra a las personas a usar el tiempo de forma diferente”. Este joven tradujo un sentimiento que pudimos observar entre ellos: la diferenciación de costumbres que adviene con el mundo universitario les presenta, y en cierto modo también les impone, nuevos desafíos en el uso del tiempo.

\section{Interrelaciones entre territorialidad y espacios de ocio}

De una manera todavía incipiente comprobamos cómo el tiempo actúa en la construcción social kaiowá/guaraní. Los procesos sociales forman habitus y tienen en el tiempo un elemento de influencia sobre las tareas humanas más específicas y sobre la dinámica de las relaciones. El tiempo es una invención humana, una institución cuya naturaleza varía conforme al desarrollo de cada sociedad (Elias, 1980).

Las representaciones sociales específicas de cada grupo se alteran en virtud de esas reconstrucciones temporales. De esa forma, el tiempo-espacio universitario dedicado al estudio, los estímulos procedentes de diferentes estancias de poder y la cotidianeidad entre diferentes mundos que penetran en las aldeas constituyen una red que modifica la auto-regulación de los indígenas. Pese a todo, en esos contextos dinámicos, con o sin resistencia "el patrimonio cultural se transmite de generación en generación [tiempo-espacio] recreando constantemente y generando un sentimiento de identidad y de comunidad" (Gallois, 2006:7)

Diem (1966) extiende a todos los humanos, indígenas y no-indígenas, la idea de que actividades como juegos, deportes, danzas, luchas y desafíos son objeto de alegría para quienes los practican y de diversión para los espectadores: producen conversaciones, son materia de conversación y noticias y poseen importancia pedagógica. Cuando los pueblos indígenas celebran y comparten colectivamente sus actividades lúdicas, incluso las agonísticas -aquellas que exigen desafíos personales o enfrentamientos entre parejas o equipos - miden sus fuerzas convirtiendo sus sociedades en una suerte de escuela que desarrolla su fuerza vital entendida como fuerza identitaria. En este sentido, el mapa de los espacios de ocio de la Tierra Indígena de Dourados es un retrato de las tensiones, conflictos, alegrías y ritos cotidianos de ese pueblo singular afectado por relaciones de contacto asimétricas que intenta reajustar el significado de su tekoha tradicional.

Como ejemplo de esa realidad, Ximenes (UFGD, 2011b) entrevistó en 2011 al Señor Gilherme, de 95 años, quien vive en la Reserva de Dourados. Este informante le dijo lo siguiente: los kaiowá/guaraní dejaron de cultivar sus propias rozas para sostener a sus familias. Antes, la selva se respetaba y de ahí que fuese grande y alta. Mas eso ha pasado a la historia porque hoy ya no hay selva en la aldea. Ya no 
existen los árboles originales ni sus frutos. Hoy se plantan árboles creados por la ciencia de los no-indígenas. Por último, relataba cómo cuidaba con celo de la vegetación que crece alrededor de su casa, vestigio de la antigua vegetación de la selva. Y, concluía, lo cuidaba porque es muy importante cuidar el medio ambiente del tekoha.

Para identificar los espacios de ocio de la Reserva de Dourados se utilizó la Ilustración 1, un mapa con carácter de fuente primaria. Tal ilustración permite señalar los espacios de ocio e inferir las actividades que allí se desarrollan. La presencia de los 3 espacios/Casa de Rezos muestra la persistencia de este pueblo a la hora de guiarse por la espiritualidad tradicional. En relación a la religiosidad, la académica indígena Ximenes (UFGD, 2011b) explica que hoy son pocas las familias que secundan este tipo de espiritualidad. Muchas se han convertido al catolicismo o siguen a los grupos evangélicos. También hay familias que no profesan tipo alguno de religión. Según una alumna, la religión pentecostal va superando paulatinamente a la espiritualidad tradicional haciendo que los kaiowá/guaraní dejen de creer en su propia cultura, en su propio modo de ser: "Hasta nuestros hijos no saben en cuál [religión] creer, o mejor, cuál seguir. Al final, acaban siguiendo la vida que lleva por el mal camino". Los mapas no registran iglesias católicas y pentecostales, de lo que deducimos que en ellas no se llevan a cabo actividades lúdicas sino exclusivamente confesionales.

Sobre los 5 espacios/escolar y atendiendo a los alumnos de las etnias Kaiowá/Guaraní, a una minoría de alumnos de la etnia Terena y a mestizos, se constatan las innumerables dificultades para proceder a un mantenimiento cualificado de los mismos. Debido a la falta de agua, una de las escuelas ya no funciona y los profesores han sido trasladados a las dependencias de otro edificio. En el día a día, las escuelas, al no tener agua, sufren para preparar la merienda o para hidratar a los niños. La merienda es fundamental si tenemos en cuenta que niños y jóvenes presentan muchas veces cuadros de déficit alimenticio o desnutrición. La alimentación escolar es insuficiente pero esencial puesto que la mayoría de las familias no posee una organización regular y diaria en la confección de alimentos. Esto responde, principalmente, a los cambios en el modo de vida tradicional que lleva a estas familias a trabajar en plantas industriales de caña de azúcar, la construcción o en la industria regional, aunque hay una minoría que sobrevive vendiendo productos extraídos de sus propias rozas (mandioca, maíz, patata dulce, plátano, caña). Incluso aún hay quienes arrendan su pequeña parte de tierra para el cultivo de soja y maíz. Muchas familias reciben apoyos del Gobierno

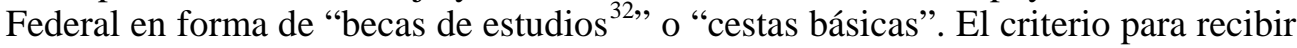
estos apoyos se fija a través del registro-catastro que exige que niños y jóvenes se matriculen y cursen la Educación Básica. El periodo de vacaciones escolares no es

${ }^{32}$ Cada niño brasileño matriculado en el curso de Educación Básica recibe esa ayuda gubernamental. 
bienvenido ya que aleja a los alumnos de la merienda y de las actividades lúdicas, como el uso de las canchas polideportivas, el teatro o la danza, que se ha recuperado como asignatura en el currículo escolar.

Imagen 1: Casa de Rezos localizada en la aldea Bororó

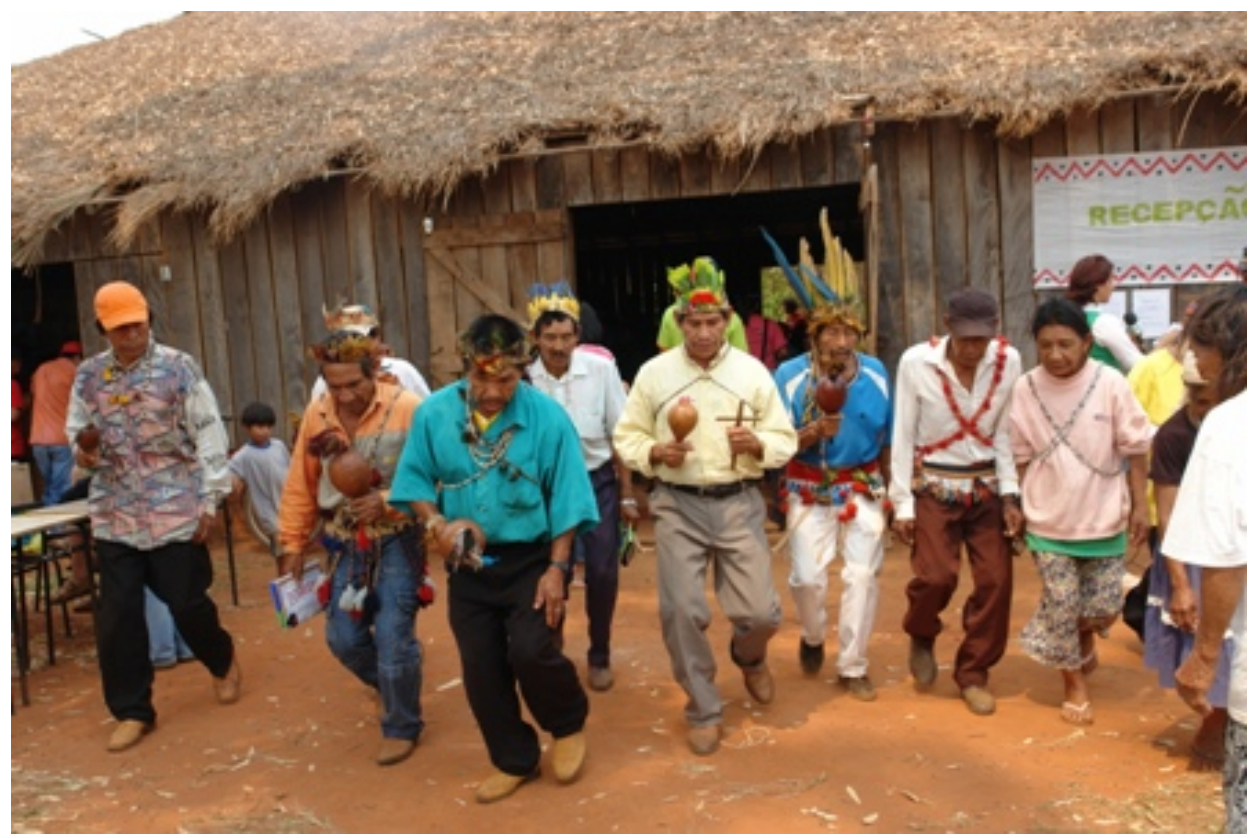

Fuente: Indiosonline (2011). Autor no especificado

Los 3 espacios/caminos vecinales serpentean el tekoha y conducen a los habitantes a sus casas sirviendo también al tráfico, cada día más intenso, de coches, carros y bicicletas. Pocas residencias siguen el patrón tradicional dada la ausencia de madera y hojas para el tejado. Por lo tanto, las casas cubiertas con lonas de plástico y otras construidas en ladrillo siguen un patrón único resultante de un proyecto gubernamental. Tradicionalmente, los caminos eran muy valorados pues por ellos se realizaban los paseos de toda la familia extensa, incluso con los animales domésticos; paseos que podían durar varios días recorriendo la selva para visitar a otros parientes y que incluían pausas para cacerías, degustaciones colectivas y actividades lúdicas en los ríos. Hoy, al anochecer, ya no se pasea más puesto que los conflictos internos y la falta de policías han reducido este tipo de actividad. La ausencia de ríos en sus tierras y la falta de vegetación contribuyeron además a la desaparición de las actividades que albergaban los caminos. Generalmente, éstos se recorren para comercializar lo que se produce en las rozas o para comprar materiales o enseres personales en el comercio de Dourados. El comportamiento recolector y cazador que identificaba a los Kaiowá/Guaraní presentaría en la actualidad un reajuste de sus significados en un sentido notablemente empobrecedor 
y patético: hoy se caracteriza por la búsqueda en los basureros de las residencias de barrios de clase media y alta; comportamiento que los descalifica a los ojos de la población lega que desconoce los condicionantes socio-históricos que venimos exponiendo en este artículo.

Imagen 2: Niños corriendo por los caminos al volver de la escuela de la aldea Bororó. En segundo plano, una vivenda de ladrillo

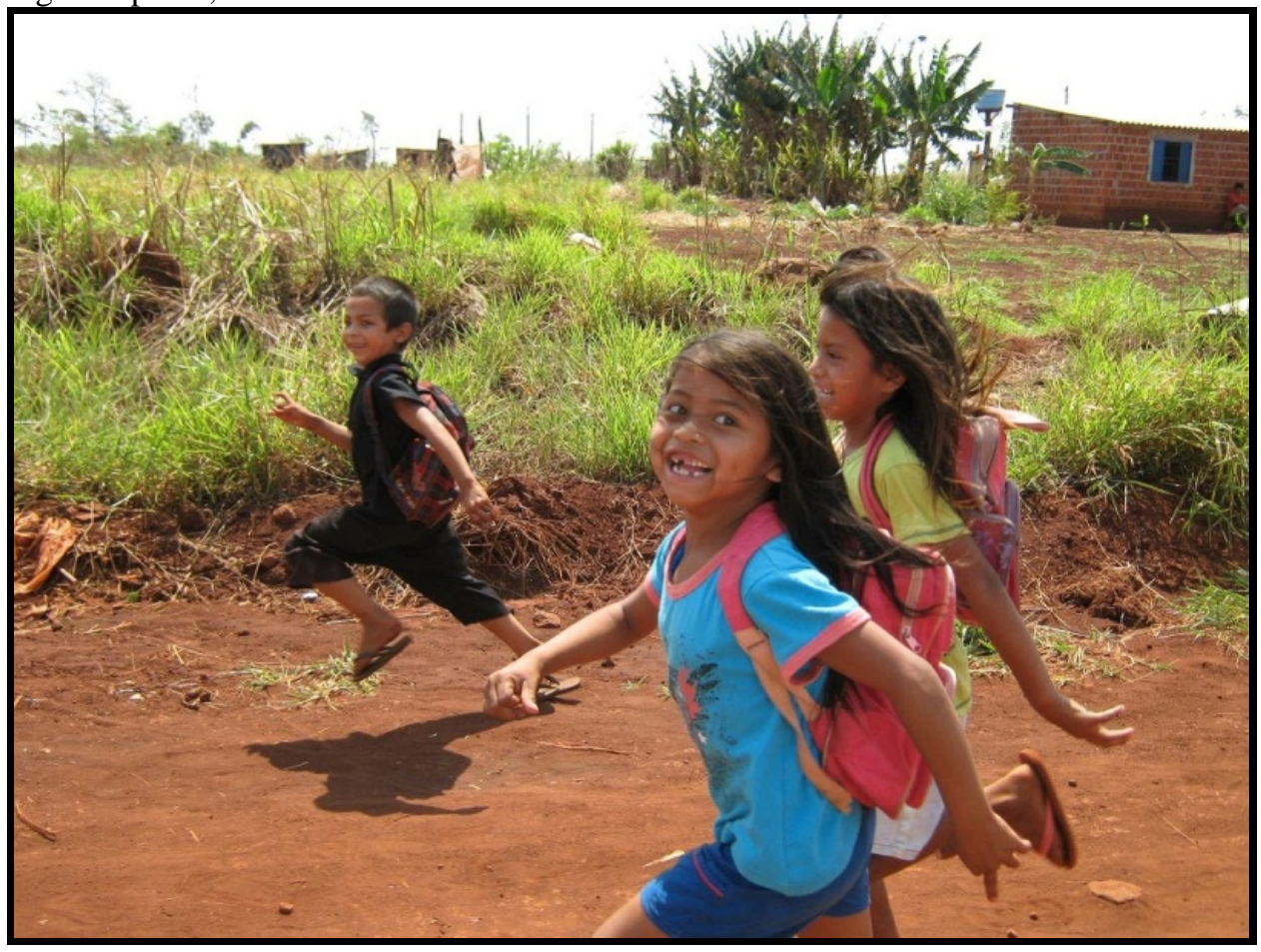

Foto: Micheli. Fuente: Educaindio (2011)

Sobre el 1 espacio/selva, éste aparece en la ilustración sin que sea mencionada la extensión del mismo. Esto apunta a una explotación desequilibrada a largo plazo, muy posiblemente efectuada por particulares durante periodos en los que fueron propietarios de la tierra y/o por los propios indígenas que tenían la costumbre de recoger madera para construir sus viviendas o emplearla para hacer fuego. Sin más tierra con la que recomponer el área utilizada, la región se ha ido agotando así como el suelo, que tarda bastante en recuperarse.

Los 13 espacios/modalidad deportiva, con campos habilitados para el fútbol, predominan y nos indican que este tipo de actividad posee una fuerte tendencia para priorizar al público masculino en la práctica futbolística, a pesar de que hemos detectado la existencia de uno o dos equipos femeninos. Las diferentes modalidades de fútbol-sala traen consigo elementos cuyas relaciones son más elaboradas y 
exigentes de acuerdo con coacciones y reglas universalizadas. El voleibol es una práctica también muy bien aceptada. No se han observado juegos con peteca ${ }^{33}$, una pequeña pelota recubierta con plumas que se lanza con la palma de la mano, aunque ésta esté presente entre los indígenas de la región sur desde 1770.

Los 3 espacios/agua son dos arroyos y un dique que hablan a las claras sobre las carencias de este elemento vital. Si pensamos en la relación cultural de los Kaiowá/Guaraní con el agua, podemos calibrar el impacto de que los límites territoriales de los márgenes de los ríos hoy ya no les pertenezcan. En su actual proceso de pauperización, cuentan con las fuentes (un total de 4) - no indicadas en la Ilustración 1 pero señaladas por otro alumno. Dos de ellas son precarias, casi cubiertas por la tierra suelta que se desprende con las lluvias fruto de la erosión y de la falta de vegetación. Hay otra que ya ha desaparecido y la que resta se encuentra en mal estado.

Imagen 3. Los niños comienzan a enfermar al beber agua no apta para el consumo humano.

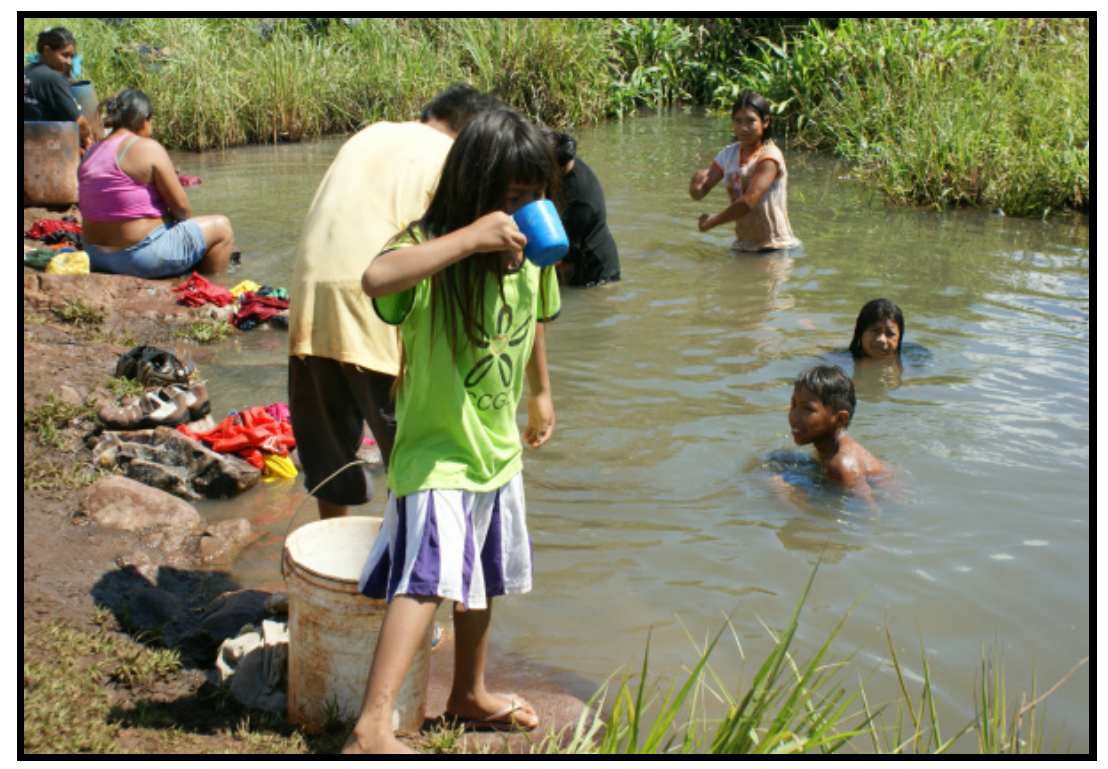

Foto: Hédio Fazan. Fuente: Douradosagora (2011)

Sobre los 3 espacios/bar, con apariencia de pubs, dos de ellos se localizan en los márgenes de la carretera BR 165 y el tercero está en la aldea Bororó. No son motivo

${ }^{33}$ Sugerimos la lectura de Vinha (2004), Corpo-sujeito Kadiwéu: jogo e esporte, para elucidação do jogo de peteca. 
de satisfacción para la población. Sus usuarios abusan del alcohol y provocan altercados que afectan a la mayor parte de los habitantes más pacíficos.

$\mathrm{Al}$ interrelacionar territorialidad y espacios de ocio teniendo como tema transversal el ocio en el sentido de alevezar (aligerar), el contexto del estudio muestra la base teórica de los procesos histórico-sociales de larga duración en el sentido dado por Elias. La jurisprudencia del derecho al ocio es de conocimiento de los indígenas de tal modo que uno de los políticos de la región obtuvo recursos federales para la construcción de una 'Villa Olímpica Indígena', inaugurada en 2010. Su utilización por parte de la comunidad se encuentra bloqueada debido a la falta de acuerdo entre los gobiernos municipales, estatales y federales en lo que toca a su mantenimiento y a la responsabilidad sobre el cuadro de funcionarios asalariados.

Imagen 4. Villa Olímpica Indígena, localizada en la aldea Bororó, el día de su inauguración.

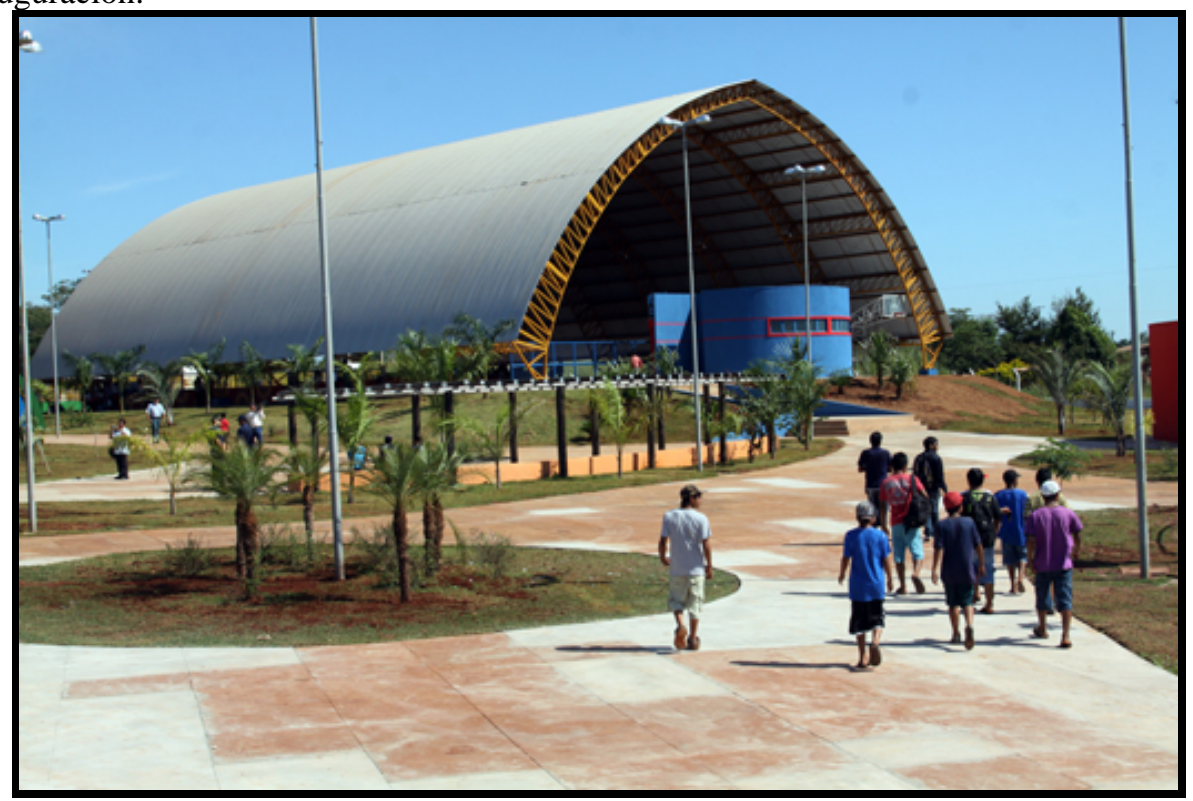

Foto: Rachid Waqued. Fuente: Phnewsms (2011)

Inaugurada en Mayo de 2011, la que se considera primera Villa Olímpica Indígena de Brasil tiene una superficie de $29.000 \mathrm{~m}^{2}$. Tiene una cancha de deportes de estructura metálica y vestuarios con un área construida de $1.116 \mathrm{~m}^{2}$. El complejo cuenta también con un campo de fútbol con vestuarios de $5.400 \mathrm{~m}^{2}$, pista de atletismo $\left(2.735 \mathrm{~m}^{2}\right)$, vóley-playa $\left(336 \mathrm{~m}^{2}\right)$ y pavimentación con $3.252 \mathrm{~m}^{2}$. "Los indígenas de las aldeas de Jaguapiru y Bororó están impacientes por utilizar la Villa 
Olímpica” publicaba el periódico Primeira Hora News en 2011, hecho que sigue sin haberse consumado en el momento en que esto escribimos, Enero de 2012.

\section{Consideraciones finales}

El presente estudio ha buscado respuesta para tres objetivos. La aprehensión del significado de la territorialidad se ha abordado a través de las respuestas ofrecidas por los indígenas Kaiowá/Guaraní acerca del tekoha. Se han abordado también los factores políticos y socio-económicos que hoy les afectan, así como muchas de las relaciones intra-aldea, actualmente desequilibradas en función del contexto general de la tierra y de la proximidad con el medio urbano del municipio de Dourados.

Las aldeas de Bororó y Jaguapiru, actualmente bajo confinamiento y, por lo tanto, viviendo bajo fuertes presiones resultantes de los conflictos por la tierra, se encuentran desde finales de 2011 sometidas a la intervención de la policía federal. La Fuerza Nacional, como se suele llamar a este tipo de intervenciones, está presente en las aldeas con el propósito de desincentivar la entrada del tráfico e intentar minimizar la violencia que se abate sobre niños y jóvenes.

Hoy los indígenas luchan políticamente por recibir agua canalizada. Curiosamente, el agua fue uno de los elementos que los diferenció de los colonizadores por la abundancia con la que la empleaban para asearse, hidratarse y divertirse. En el tekoha Bororó y Jaguapiru es frecuente que los niños se presenten cubiertos de tierra roja, con el pelo endurecido por el polvo y las ropas degradadas, producto también de las fuentes bloqueadas por la acumulación de residuos sólidos, por la ausencia de ríos al quedar éstos en áreas privadas y por los obstáculos que coloca el poder público a la hora de canalizar el agua.

El ocio existía en los tekoha vinculado al ara. Hoy, el tiempo está cada vez más expuesto a la condición de la invención humana, una institución cuya naturaleza varía conforme al desarrollo de cada sociedad. El tiempo se alía al espacio y a su construcción, de tal forma que las representaciones sociales específicas de los Kaiowá/Guaraní se van alterando - aunque esto resulte imperceptible para ellos conforme también a las construcciones temporales. Así, el tiempo se combina con diferentes espacios - el universitario, dedicado a los estudios; el político, con las provocaciones que llegan desde las instancias del poder; el de las Casas de Rezo tradicionales -; espacios que forman y amplían la red de interrelaciones que modifica la autorregulación de los indígenas alterando su tekoha.

En el seno de las cadenas de relaciones, el tiempo se erige como una construcción intelectual dentro de cada cultura (Elias, 1980). Sin embargo, sabemos que "todavía hoy el estatuto ontológico del tiempo sigue siendo, en general, oscuro. Meditamos sobre él sin saber muy bien a qué tipo de objeto nos enfrentamos" (Elias, 1998:14). En la singularidad Kaiowá/Guaraní, la construcción social del tiempo se apoya en la cosmología y se percibe como un mundo unitario regido por espíritus y por fuerzas sobrenaturales. Esta percepción es cuestionada a día de hoy por elementos notablemente complejos: el tipo de poder subyacente a los 
acontecimientos que provocan miseria y tristeza, el tipo de poder que les impone la organización política para planificar sus luchas actuales o la posibilidad de retomar su rica espiritualidad, hoy amenazada por un dios único.

Por lo tanto, para aligerar su modo de vida actual, los Kaiowá/Guaraní tienen en los resultados todavía parciales de este estudio la identificación de los espacios que sugieren prácticas en las que se mimetizan los desafíos y se revitalizan las fuerzas para reajustar y recuperar el modo 'frío', no caliente, no nervioso, que marca su identidad. Sabemos que las figuraciones humanas, en sus diversas sociedades, no se desarrollan en línea recta. Comportan retrocesos, zigzags, desvíos y no son absolutas mas sí resultantes de procesos ciegos. Tenemos sociedades que, viviendo en un mismo tiempo histórico, adoptan pocos instrumentos artificiales para medir el tiempo y se mantienen relativamente autónomas, mientras otras lo mensuran minuciosamente en un campo amplio de interrelaciones. Para nosotras, como investigadoras, todo eso no sería grave si la supervivencia no llamase a la puerta. Festejos, juegos, danzas y ritos realizados en el restringido tekoha kaiowá/guarani pueden ser acciones que fortalezcan sus identidades, en un momento como el actual en el que dialogan con lo nuevo, lo inesperado, lo invasivo o incluso con lo que es rechazado. Todo ello deriva de la ampliación de la red de interrelaciones y de las asimetrías de las relaciones de poder. Pese a la gradual adquisición de conciencia de que el tiempo y el espacio lúdicos son construcciones, permanece el hecho de unos Kaiowá/Guaraní que se identifican como alegres. 'Somos pueblo de la selva, somos gente alegre’ nos dicen.

\section{Bibliografía}

Borges, L. (2002): “Os Guarani Mbyá e a Categoria Tempo”. Revista Tellus, NEPPI/Campo Grande: UCDB, año, 2, n. 2, p. 105-122.

Brand A. J. e Vietta, K. (2001): "Análise gráfica das ocorrências de suicídios entre os Kaiowá/Guarani, no Mato Grosso do Sul, entre 1981 e 2000”. Revista Tellus, año 1, n. 1, p. 119-132. Campo Grande - MS

Brand, A. J.; Azevedo, M.; Colman, R.S. (2011) "Os Guarani nas fronteiras do MERCOSUL e suas demandas por políticas públicas adequadas”. Disponible en: http://www.neppi.org/producoes.php?id=130 . Texto publicado no Livro: Educación, lenguas y culturas en el Mercosur: pluralidad cultural e inclusión social en Brasil y en Paraguay. (Org.): José Maria Rodrigues. Consulta: 20.01.2012.

Brand, A.J. (1993) O confinamento e seu impacto sobre os Paì-Kaiowá. Dissertação. Pontifícia Universidade Católica do Rio Grande do Sul. Porto Alegre.

Brasil (1988): Constituição da República Federativa do Brasil de 1988. Publicada el 5 Octubre de $1988 . \quad$ Disponible en: http://www.planalto.gov.br/ccivil_03/Constituicao . Consulta: 20 Enero 2012. 
CIMI - Conselho Indigenista Missionário (2010): Aty Guasu recebe prêmio Direitos Humanos 2010. Disponible en: http://www.cimi.org.br . Post: 13/12/2010. Consulta: 23/2/2012.

Colman, R. S. (2007): “Território e Sustentabilidade: os Guarani e o Kaiowá de Yvi Kitu”. (Dissertação). Universidade Católica Dom Bosco, Campo Grande, MS.

Diem, C. (1966): Celebrar e Competir.

Ecoamazonia (2011): Censo conta 817 mil indígenas no Brasil. Autor: AGOSTINHO, J. Publicado: 4/5/2011. Disponible en: http://www.ecoamazonia.org.br/2011/05/censo-conta-817-mil-indigenas-nobrasil/

Elias, N. (1980): Introdução à Sociologia. Lisboa: Edições 70.

Elias, N. (1992): "Introdução”. A Busca da Excitação. (Org) Norbert Elias \& Eric Dunning (Org). Portugal: DIFEL Editora.

Elias, N. (1998): Sobre o Tempo. Rio de Janeiro: Zahar,

Fassheber, J.R. (2006): Etno-Desporto Indígena: contribuições da antropologia social a partir da experiência entre os Kaingang. Campinas, SP: [s.n].

Gallois, D. T.(2006): "Patrimônio Cultural Imaterial de Povos Indígenas". Documento Base - $2^{\circ}$ Seminário Regional do Iepê: Experiências Indígenas em gestão e pesquisa de patrimônios culturais no Amapá e norte do Para. Disponible

en: www.institutoiepe.org.br/docs/DocBase_seminario_iepe_2005.pdf

Houaiss (2007): Dicionário Houaiss da Língua Portuguesa. Rio de Janeiro: Objetiva.

IBGE (2010): Sinopse do Censo Demográfico 2010. Publicado: 19/4/2011. Consulta: www.ibge.gov.br/home/estatistica/populacao/censo2010/default_sinopse.shtm. Dia 20.01.2012.

Junqueira, C. (2002): “Antropologia Indígena: uma introdução, história dos povos indígenas no Brasil”. São Paulo, EDUC (Série Trilhas).

Landa, B. S. (2005): "O uso do espaço da Terra Indígena Porto Lindo/Jakarey, município de Japorã/MS através da abordagem etnoarqueológica”. In: XIII Congresso da SAB, 2005, Campo Grande. Anais do XIII Congresso da SAB.

Larousse Cultural (1992): Dicionário Larousse Cultural - dicionário da Língua Portuguesa. Editora Nova Cultural: SP.

Marcellino, N. C. (2000): Mirando la educación desde la Recreacion. CórdobaArgentina, Septiembre de 2000, no. 16, pp.2 a 6, Conferencia n 2.

Marcellino, N.C. (2005). “Estudos Do Lazer - Uma Introdução”. Editora Papirus. Melià, B. (2010): “Juego y arte en movimiento". Apresentação do livro Ñemborari. Secretaria de Estado de Educação, Mato Grosso do Sul.

Pereira, L. M. (2009): "Falta conversa e entendimento”. Jornal online Midiamax Entrevista concedida à jornalista Fernanda Brigatti, publicada dia 16/08/2009, 15:39. Consulta: http://www.midiamax.com/view.php?mat_id=523027. Dia 25/08/2009. 
Pereira, L.M. (2010): Demarcação de Terras kaiowá e guarani em MS: ocupação tradicional, reordenamentos organizacionais e gestão territorial. Revista Tellus, año 10, n.18, p.115-137, Enero/Junio 2010. Campo Grande - MS.

Phnewsms (2011): Imagem 4. Vila Olímpica Indígena, localizada na aldeia Bororó, no dia da sua inauguração. Foto: Rachid Waqued. Obtido em: www.phnewsms.com.br . Consulta: 20/1/ 2011.

Rocha Ferreira, M. B. et al. (2005): "Raízes”. Atlas do Esporte no Brasil: Atlas do Esporte, Educação Física e Atividade Física, Saúde e Lazer no Brasil. (Org.) Lamartine A. Costa. Rio de Janeiro: Shape.

UFGD (2009): Acervo de trabalhos dos alunos do Curso de Licenciatura Intercultural Indígena Teko Arandu. (não publicado).

UFGD (2010): Projeto Pedagógico do Curso de Licenciatura Intercultural Indígena Teko Arandu. Disponible en: www.ufgd.edu.br/licenciaturaindigena/donwloads . Consulta: 20/1/2011.

UFGD (2011b): Loide Ximenes entrevistou Sr. Guilherme - ancião da aldeia Bororó. Dourados - MS (não publicado).

Vinha, M.; Nascimento, A. C. (2009): Educacion Guarani Y Kaiowá Y los Procesos Civilizadores Eliasianos: Ensayos. In: Carina Kaplan; Victoria Orce (coord.). (Org.). Procesos Civilizadores y Cultura. $1^{\mathrm{a}}$ ed. Buenos Aires: Noveduc, 2009, p. 165-172.

Vinha, M. e Rossato, V. L. (2009): "Para Alevezar os Guarani e Kaiowá”. XII Simpósio Internacional Processo Civilizador, Recife.

\section{Imágenes}

Indioeduca (2011): Imagem 2. “Crianças Kaiowá voltando da escola na Aldeia Bororó-Dourados/MS”. Disponible en: http://www.indioeduca.org. Publicado por Micheli em 10.10.2011. Consulta: 20/1/2012.

Indiosonline (2011): Imagem 1. "Casa de Reza - aldeia Bororó”. Obtido em: http://www.indiosonline.net. Publicada: 23/10/2007 (sem autoria). Consulta: 20/1/2011

Douradosagora (2011): Imagem 3. Indígenas disputam água de riacho na Aldeia Bororó. Foto: Hédio Fazan. Fonte: www.douradosagora.com.br . Publicada: 29/12/2011, 10h16. Consulta: 20/1/ 2012.

UFGD (2011a): Ilustração 1. Raica Martins e o Mapeamento dos Espaços de Lazer da Reserva Indígena Francisco Horta Barbosa, Dourados - MS. (não publicado) 